\title{
Upper Jaw Molar
}

National Cancer Institute

\section{Source}

National Cancer Institute. Upper Jaw Molar. NCI Thesaurus. Code C49795.

Any of the molars located in the upper jaw. 